\section{Mixed connective tissue disease, overlap syndromes, and eosinophilic fasciitis}

\author{
P J Maddison
}

While the cause of connective tissue diseases (CTDs) remains unknown the classification of individual patients will continue to depend on identifying certain patterns of clinical and laboratory features. This is the basis of the various classification criteria for systemic sclerosis, ${ }^{1}$ systemic lupus erythematosus (SLE), ${ }^{2}$ and other connective tissue diseases. As many as $25 \%$ of patients with CTD, however, present with overlapping clinical features. The term 'overlap syndrome' is applied to what appears to be a very heterogeneous group of disorders, though features associated with systemic sclerosis are often a major component. Frequently, patients have a mild CTD characterised by Raynaud's phenomenon, oedema of the hands, and, possibly, acrosclerosis and arthritis, which has been termed 'undifferentiated CTD'. ${ }^{3}$ Other patients present manifestations of more than one definite CTD and commonest among these are disorders with features of systemic sclerosis combined with those of $\mathrm{SLE}^{4}$ or polymyositis, or both, with features of systemic sclerosis or SLE and rheumatoid arthritis, ${ }^{67}$ and features of Sjögren's syndrome in association with any of the other CTDs. Overlapping features may occur concurrently, but more commonly over time one syndrome takes on the features of another. It is still contentious whether or not overlap syndromes represent the coexistence of separate diseases, the broad clinical expression of one of the rheumatic diseases, or distinct clinical entities with distinctive aetiology and pathogenesis.

In some cases overlap syndromes are associated with a particular serological marker (table 1). Antibodies to the RNA binding proteins Ro (SSA) and La (SSB) are associated with Sjögren's syndrome developing in association with other CTDs, such as systemic sclerosis or SLE. Recent reviews suggest that Sjögren's syndrome in this context resembles primary Sjögren's syndrome and differs significantly from secondary Sjögren's syndrome accompanying rheumatoid arthritis. ${ }^{8}$ Severe xerophthalmia, xerostomia, and parotid gland enlargement are often
Royal National Hospital for Rheumatic Diseases and School of Postgraduate Medicine, University of Bath, Bath BAI 1RL P J Maddison prominent, resembling primary Sjögren's syndrome, in which these features are common. This contrasts with secondary Sjögren's syndrome accompanying rheumatoid arthritis, in which they are uncommon.

Antibodies to PM-Scl (PM-1), a nucleolar antigen, ${ }^{9}$ and $\mathrm{Ku}$, a DNA binding nuclear protein complex composed of two polypeptides of 86 and $70 \mathrm{kD},{ }^{10}$ identify patients with overlap features of polymyositis and systemic sclerosis. Antibodies to histidyl t-RNA synthetase identify patients with polymyositis who develop interstitial pulmonary disease. ${ }^{11}$

Possibly, CTDs represent a genetically determined host response to a number of environmental triggers. A number of studies, for example, have shown that the presence of certain HLA class II genes is associated with specific immune responses to autoantigens such as Ro and La, ${ }^{12}{ }^{13}$ UIRNP, ${ }^{13} \mathrm{Ku},{ }^{14}$ and Jo-1. ${ }^{15}$

\section{Mixed connective tissue disease}

Mixed connective tissue disease (MCTD) was initially described in 1972 by Sharp and coworkers $^{16}$ as a unique syndrome with features of SLE, systemic sclerosis, and myositis associated with antibodies to a nuclear ribonucleoprotein, U1RNP. Subsequently, the serological specificity was defined to epitopes on the $70 \mathrm{kD}$ phosphoprotein uniquely associated with the ribonucleoprotein particle containing U1RNA. ${ }^{17}$ The original claims for MCTD have subsequently become points of contention. These include the clinical distinctiveness, based on the presence of a particular group of featuresnotably, Raynaud's phenomenon, arthralgias and arthritis, puffy hands, abnormal oesophageal motility, myositis, and lymphadenopathy and by the absence of cerebral and renal disease and vasculitis, a benign prognosis, responsiveness to corticosteroids, and the presence of high titres of anti-UlRNP.

Since 1972 our concepts of this condition have evolved and the original claims require considerable modification. Organ involvement is often extensive and there is a tendency to evolve away from a 'mixed' clinical picture so that many patients eventually develop the unequivocal picture of a classical CTD, most often systemic sclerosis. The problem remains as to whether or not MCTD, being essentially serologically defined, warrants the status of an independent disease.

The lack of consensus as to whether MCTD is a specific entity is due to a lack of criteria for its diagnosis. Recently, at a meeting in Japan, three different sets of criteria were described ${ }^{18}$ polymyositis
pystemic sclesis

Polymyositis/interstitia

pulmonary disease
Mixed connective tissue
Ku-Scl (PM-1) DQw1

Jo-1 DRw52 
(shown in the appendix) and subsequently Alarcon-Segovia and Cardiel ${ }^{19}$ compared these criteria in a large group of subjects with connective tissue disease. The group included patients considered to have genuine MCTD, all of whom were positive for anti-U1RNP, together with groups of patients fulfilling classification criteria for systemic sclerosis, dermatomyositis or polymyositis, primary Sjögren's syndrome, SLE, and rheumatoid arthritis. Table 2 summarises the results, showing that all three sets of criteria fared similarly in capturing nearly all the patients with MCTD and distinguishing them from those with other defined CTDs. Alarcon-Segovia's criteria are simple compared with the others, comprising five clinical manifestations in addition to the serological status. Thus it is suggested by the authors that MCTD has a group of core manifestations and the occurrence of these early in the course of the disease permits diagnosis of MCTD in the absence of anti-U1RNP, which may appear later.

The basic premise is that the presence of high titres of antibodies to U1RNP modifies the expression of a CTD in ways that are relevant to prognosis and treatment. To avoid a circular argument there is a need to include patients in studies with overlap features irrespective of serological findings. There are only a few reports analysing overlap syndromes defined by clinical criteria alone, ${ }^{20} 21$ and in these, antibodies to U1RNP fail to identify a distinctive clinical group. Lazaro and Morteo, ${ }^{21}$ for example, evaluated the influence of anti-U1RNP in a group of 27 patients with overlap features and concluded that the range of clinical manifestations was unrelated to the presence or absence of these antibodies. Antibodies to U1RNP have been known to disappear during the course of the disease, ${ }^{22}$ however, and prospective clinical studies are now required.

The cause of MCTD is unknown. The transient appearance of antibodies to U1RNP has been reported during treatment with procainamide, ${ }^{23}$ but drugs have not been associated with the clinical syndrome. Interestingly, Khan et al reported four patients with MCTD and antibodies to U1RNP who were exposed during the course of their occupation to vinyl chloride. ${ }^{24}$ The clinical picture in these cases contrasts with 'vinyl chloride disease', which is characterised

Table 2 Concordance of three sets of criteria with clinical diagnosis of mixed connective tissue disease (MCTD) in 593 patients with connective tissue disease. (After Alarcon Segovia and Cardiel, 1989)

\begin{tabular}{|c|c|c|c|}
\hline \multirow[t]{2}{*}{ Behaviour (n) } & \multicolumn{3}{|c|}{$\begin{array}{l}\text { Criteria } \\
\text { \% Concordance with clinical diagnosis }\end{array}$} \\
\hline & $\begin{array}{l}\text { Alarcon-Segovia } \\
\text { and Cardiel }\end{array}$ & Sharp & $\begin{array}{l}\text { Kasukawa } \\
\text { et al }\end{array}$ \\
\hline 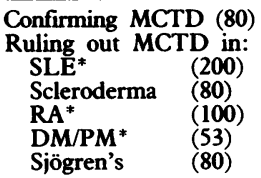 & $\begin{array}{r}100 \\
99 \\
100 \\
100 \\
100 \\
99\end{array}$ & $\begin{array}{c}100+ \\
87 \cdot 5 \\
55 \\
100 \\
84 \\
96\end{array}$ & $\begin{array}{r}96 \\
100 \\
100 \\
100 \\
100 \\
99\end{array}$ \\
\hline
\end{tabular}

${ }^{*}$ SLE =systemic lupus erythematosus: $R A=$ rheumatoid arthritis; $\mathbf{D M} / \mathbf{P M}=$ dermatomyositis/polymyositis $+57 \cdot 5 \%$ as definite, $42 \cdot 5 \%$ as probable. by Raynaud's phenomenon, striking acroosteolysis and, sometimes, scleroderma-like skin changes. ${ }^{25}$ In this disorder specific autoantibodies have not been detected. ${ }^{26}$ The association with toxic exposure in these cases of MCTD might be merely coincidental. As three cases of MCTD have previously been reported after breast augmentation surgery, ${ }^{27}$ however, the question is raised whether or not a variety of environmental insults can induce clinical and serological features of MCTD in a patient with a particular genetic background.

There are familial cases of MCTD but, until recently, no haplotype association has been described. Black and coworkers showed an increased instance of HLA-DR4 in patients with MCTD compared with controls ${ }^{28}$ (table 3 ). The association, however, was only significant in patients with polyarthritis, some of whom had erosive disease, though there was no association with rheumatoid factor. The association, therefore, is related to a particular pattern of disease expression rather than to MCTD per se. On the other hand, there was a significant alteration in the $\mathrm{Gm}$ allotype frequencies in patients with MCTD. This Gm association may be particularly important because $\mathrm{Gm}$ associations are not well defined for rheumatoid arthritis, SLE, or systemic sclerosis. More recently, the presence of autoantibodies to UIRNP both in association with MCTD and SLE has been strongly linked to the $D Q \beta$ gene associated with DQw7, 8, and 9. ${ }^{13}$

The prevalence of MCTD is not known precisely but it is generally considered to be more common than systemic sclerosis and polymyositis but less common than SLE. There is a marked female preponderance (about $8 \mathrm{~F}: 1 \mathrm{M})$ and apparently no ethnic group is particularly susceptible. Cases are recognised in children. It has been suggested that MCTD produces more morbidity in children with a higher prevalence of features such as significant myocarditis, glomerulonephritis, thrombocytopenia, seizures, and aseptic meningitis. These observations, however, may be the result of a selection bias.

The initial presentation is rarely distinctive and often comprises Raynaud's phenomenon, swollen puffy hands, polyarthritis, and rash. As the disease evolves, overlapping features tend to

Table 3 Prevalence of DR4 and major Gm phenotypes in patients with mixed connective tissue disease (MCTD) and normal controls. Results are shown as the percentage of subjects

\begin{tabular}{lclc}
\hline & $\begin{array}{c}M C T D \\
(n=31)\end{array}$ & $\begin{array}{l}\text { Controls } \\
(n=200)\end{array}$ & $\chi^{2}$ \\
\hline DR4 & 48 & 32 & \\
Gm phenotypes* & with arthritis 62 & & $4 \cdot 93$ \\
Gm 1.3 & $64 \cdot 5$ & 31 & $11 \cdot 7$ \\
Gm 2.3 & 13 & 15 & $5 \cdot 3$ \\
Gm 3 & $19 \cdot 4$ & 43 & \\
Gm 2 & 3 & 6 & \\
\hline
\end{tabular}

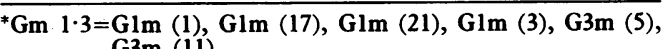
G3m (11)

Gm 2.3=Glm (1), Glm (2), Glm (17), Glm (21), Glm (3), G3m (5), G3m (11)

Gm $3=$ Glm (3), G3m (5), G3m (11)

Gm $1=$ Glm (1), Glm (17), Glm (21)

Gm 2 =Glm (1), Glm (2), Glm (17), Glm (21) 
occur sequentially. A broad spectrum of manifestations is seen (table 4). Features reported to be particularly characteristic of MCTD, occurring more commonly there than in other CTDs, include an erosive arthritis, multiple subcutaneous nodules in the peritendinous regions of the forearms and hands, juxta-articular calcinosis, and pulmonary hypertension.

Polyarthritis is a prominent feature and is somewhat more severe than in typical SLE. There is a tendency to develop deformities of the hands and feet as a result of periarticular involvement leading to ligamentous and capsular laxity. ${ }^{29}$ Sometimes erosions are seen radio-

Table 4 Cumulative clinical manifestations in mixed connective tissue disease

\begin{tabular}{ll}
\hline Clinical manifestation & Prevalence (\%) \\
\hline Skin and mucous membranes & 60 \\
Swollen hands & 50 \\
Rash & 45 \\
Mucosal ulceration & 40 \\
Sclerodactyly & 10 \\
Gottron's papules & Rare \\
Heliotrope & \\
Musculoskeletal & 80 \\
Arthritis & 70 \\
Myalgias & 40 \\
Nodules & 30 \\
Jaccoud's arthropathy & 25 \\
Myositis & 20 \\
Erosions & \\
Gastrointestinal & 75 \\
Reduced oesophageal motility & Rare \\
Malabsorption & Rare \\
Pseudodiverticula & \\
Cardiovascular & 95 \\
Raynaud's phenomenon & 40 \\
Pericarditis & 40 \\
Pulmonary hypertension & Rare \\
Myocarditis & \\
Respiratory & 75 \\
Reduced co transfer & 50 \\
Pleurisy & \\
Neuropsychiatric & \\
Trigeminal neuropathy & \\
Aseptic meningitis & \\
Renal & \\
Glomerulonephritis & \\
Hypertensive crisis & \\
\hline & \\
& \\
\hline
\end{tabular}

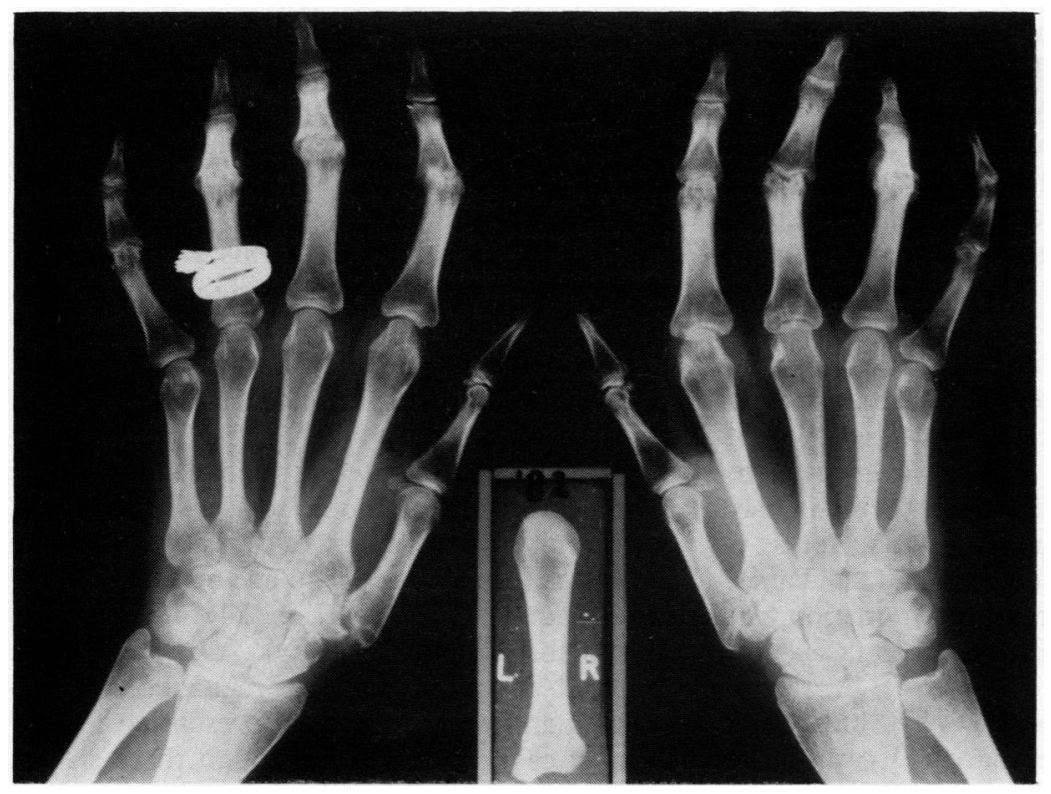

Figure 1 Hand radiographs of a patient with mixed connective tissue disease showing erosive arthropathy, particularly affecting the proximal interphalangeal and first carpometacarpal joints. logically and can be extensive, mainly affecting the interphalangeal and first carpometacarpal joints (fig 1). In MCTD an association has been noted between arthritis and the presence of HLA-DR4. ${ }^{26}$ Rheumatoid factor is detected in about $50 \%$ of cases, and $40 \%$ have small, often multiple, subcutaneous nodules over the flexor tendons of the forearms, extensor tendons of the hands close to the metacarpophalangeal and proximal interphalangeal joints, extensor tendons on the dorsum of the foot, and over the Achilles tendon. Histologically they show nonspecific inflammation and not the typical morphology of rheumatoid nodules. ${ }^{21}$

The most common neurological complication is trigeminal neuropathy. Interestingly, this is also a neurological manifestation of systemic sclerosis but is uncommon in more typical cases of SLE. ${ }^{30}$ Vascular headaches, often with features of migraine are common, but other neurological complications are rarely seen. Similarly, clinically significant glomerulonephritis is uncommon, though cases of membranous nephropathy have been seen. ${ }^{31}$

Abnormal lung function tests, especially the single breath diffusing capacity, are abnormal in most patients, but only a minority are symptomatic. ${ }^{32}$ Pulmonary hypertension, however, is an increasingly recognised complication. Sometimes this is secondary to interstitial pulmonary fibrosis but more commonly is a primary event associated with intimal proliferation of pulmonary arterioles. Those affected often have a poor prognosis and right ventricular failure can progress rapidly. ${ }^{33}$

Involvement of the pulmonary arterioles is part of a generalised vasculopathy which characterises MCTD and dominates the clinical picture in a minority of patients. There are a few descriptions, for example, of intimal proliferation of renal vessels, resembling that seen in systemic sclerosis, resulting in hypertensive crisis and renal failure. ${ }^{34}$ At least $50 \%$ have nailfold capillary changes similar to those found in systemic sclerosis. ${ }^{35}$ Angiography has been used to show organic obstruction of digital vessels in a large proportion of patients with MCTD, emphasising the propensity of these patients to develop vasculopathy of both small and medium sized vessels. ${ }^{36}$

Proteins complexed in small nuclear ribonucleoprotein particles (snRNPs) to uridylic $\operatorname{acid}(\mathrm{U})$ enriched snRNAs are important targets for autoimmunity in CTDs. As summarised in table 5 these snRNPs have at least seven core

Table 5 Association of proteins with snRNAs in the major snRNPs

\begin{tabular}{|c|c|c|c|c|}
\hline \multirow[t]{2}{*}{ Protein } & \multirow{2}{*}{$\underset{(k D)}{M o l} w t$} & \multicolumn{3}{|c|}{ snRNA } \\
\hline & & $\overline{U I}$ & $U 2$ & $U 4,5,6$ \\
\hline $70 \mathrm{kD}$ & $\begin{array}{l}70 \\
32\end{array}$ & $\begin{array}{l}+ \\
+\end{array}$ & & \\
\hline $\mathbf{A}^{\prime}$ & 31 & + & + & \\
\hline $\begin{array}{l}\mathbf{B}^{\prime} \\
\mathbf{B}^{\prime \prime}\end{array}$ & 27 & + & + & + \\
\hline $\begin{array}{l}\text { B } \\
\text { B }\end{array}$ & $\begin{array}{l}26 \\
25\end{array}$ & + & $\begin{array}{l}+ \\
+\end{array}$ & + \\
\hline C & 22 & + & & \\
\hline D & 16 & + & $\stackrel{+}{+}$ & + \\
\hline $\begin{array}{l}\mathbf{D} \\
\mathbf{E}\end{array}$ & $\begin{array}{l}15 \\
12\end{array}$ & $\begin{array}{l}+ \\
+\end{array}$ & + & $\begin{array}{l}+ \\
+\end{array}$ \\
\hline$\vec{F}$ & 11 & + & + & + \\
\hline G & 9 & + & + & + \\
\hline
\end{tabular}


proteins in common and a varying number of particle specific proteins. Antibodies to UIRNP recognise three polypeptides, termed $70 \mathrm{kD}, \mathrm{A}$, and $C$, found uniquely in association with U1RNA (reviewed in ref 37). The great majority of serum samples containing antiUIRNP react with $70 \mathrm{kD}$ and $A$ with fewer reacting with the $C$ polypeptide. About $60 \%$ of serum samples react with $\mathrm{BB}^{\prime}$. cDNA clones coding for these proteins have been cloned, and assays based on recombinant antigens have been developed by some laboratories to identify antibodies to UIRNP of particular specificity. ${ }^{38}$ Another method for doing this, which is currently more accessible, is the Western technique of immunoblotting. It has been suggested that the reaction of antibodies with the $70 \mathrm{kD}$ polypeptide of U1RNP is an important serological marker for MCTD, whereas antibodies to U1RNP in MCTD associated with SLE are directed to epitopes on other polypeptides, particularly $\mathbf{B B}^{\prime} .^{17} 28$ This, however has not been our experience, and during the course of a 10 year prospective clinical study of antiUIRNP positive patients we found anti-70 kD with equal prevalence in patients satisfying the criteria for MCTD and SLE. ${ }^{39}$ Long term follow up of large numbers of patients is required to resolve this.

In most patients the antibody profile to UIRNP is detected at the initial presentation with clinical disease and remains constant during the course. Occasionally, the antibody profile evolves after the disease has presented or, alternatively, the antibodies subsequently disappear. ${ }^{22}$ Antibody titres sometimes fluctuate but do not accurately reflect clinical disease activity. ${ }^{40}$

Antibodies to single stranded DNA, histones, and cardiolipin occur with a prevalence seen in SLE. Antibodies to double stranded DNA are uncommon, however, as are antibodies to other ribonucleoprotein antigens, such as Sm, Ro, and La.

Mixed connective tissue disease in many patients has a benign course, but a follow up by Nimelstein et $a l^{34}$ of the original 25 patients described by Sharp in 1972 showed that the prognosis is not invariably favourable. Although clinically significant glomerulonephritis and neuropsychiatric disease is uncommon, some patients develop life threatening complications, such as pulmonary hypertension.

Eosinophilic fasciitis

Eosinophilic fasciitis is generally recognised by the often rapid appearance of tender swelling of the arms and legs that evolves over days to weeks into brawny induration, which may closely resemble systemic sclerosis. This is associated with blood eosinophilia and a characteristic histological picture of inflammation and sclerosis primarily affecting the deep fascia and subcutis.

The first published report was by Shulman in 1975. ${ }^{41}$ Since then more than 200 cases have been reported and the full extent of the clinical spectrum is becoming known. Some consider eosinophilic fasciitis to be part of the spectrum of systemic sclerosis as after one or two years a large proportion of patients develop chronic fibrotic and atrophic cutaneous features and some develop systemic manifestations of systemic sclerosis. There are significant differences that seem to set eosinophilic fasciitis apart from systemic sclerosis, however. These include the relative absence of Raynaud's phenomenon, normal nailfold capillaries, sparing of the epidermis and dermis, infrequent visceral involvement, absence of the serological features which characterise systemic sclerosis, and the development of haematological complications, such as aplastic anaemia and thrombocytopenia, which are extremely rare in typical systemic sclerosis. $^{42}$

The cause is unknown. Multiple cases within a family with sharing of HLA genes has been reported, suggesting that genetic factors may be involved. ${ }^{43}$ An interesting feature is the association of many cases with strenuous exertion, especially in men. There has been speculation that there is a hypersensitivity reaction to muscle tissue following exercise induced damage, but there may be multiple aetiological triggers. A temporal association has been reported with cancer, ${ }^{44}$ and the administration of drugs such as those used in antituberculous treatment ${ }^{45}$ and phenytoin. ${ }^{46}$ Although exposure to toxic agents has been suggested in the pathogenesis of eosinophilic fasciitis, there is no evidence for this in most cases. Recently, there have been increasing reports, particularly from the USA, of L-tryptophan induced 'eosinophilia-myalgia syndrome', some cases of which closely resemble eosinophilic fasciitis. ${ }^{47} 48$ Consumption of Ltryptophan has been implicated, which is sold over the counter for a variety of neuropsychiatric disorders, insomnia, and various musculoskeletal complaints. Features of the syndrome include marked peripheral eosinophilia, intense myalgias, and sensory symptoms, which can progress to a severe neuromuscular disorder with axonal degeneration and myopathy, constitutional symptoms with fever and pulmonary manifestations, resembling Löffler's syndrome. About one third of patients develop oedema and cutaneous induration, mainly affecting the extremities, similar to eosinophilic fasciitis. ${ }^{49}$ Interestingly, abnormal tryptophan metabolism has been postulated in both idiopathic scleroderma and eosinophilic fasciitis. ${ }^{50}$ Raised basal urine and plasma concentrations of kynurenine have been reported as well as higher concentrations after L-tryptophan loading. The possibility of a toxic contaminant of L-tryptophan in cases of eosinophilia-myalgia syndrome has not been excluded, however.

In contrast with systemic sclerosis, the female to male ratio in eosinophilic fasciitis is about equal. In a recent review of 52 patients seen at the Mayo Clinic $^{51}$ the mean age of onset was 47 years (range 11-72) and in $24(46 \%)$ it was related to strenuous exertion. A case has been reported to occur during pregnancy. ${ }^{52} \mathrm{Cuta}$ neous manifestations are the presenting feature in most cases and evolve through three stages: pitting oedema, which is frequently present at onset, peau d'orange or dimpling, and induration. These stages are often present 
simultaneously in different areas of the body and virtually any part of the body can be involved, but the face is not usually affected. The arms and legs are most commonly affected (fig 2) and, in contrast with previously held views, simultaneous involvement of hands and feet is not uncommon. Not previously emphasised is the fact that localised morphoea may occur. Joint contractures, particularly of the elbows, ankles, and knees, are common, resulting from induration and sclerosis of subcutaneous tissue. Carpal tunnel syndrome is commonly described and occurs in about $25 \%$ of patients, sometimes preceding the skin manifestations.

Systemic involvement is more common than previously thought. There have been isolated cases of oesophageal, pulmonary, or cardiac involvement, but in contrast with systemic sclerosis there is relative sparing of the viscera. On the other hand, synovitis is common and may be the presenting feature. Sometimes there is a symmetrical polyarthritis which resembles rheumatoid arthritis, and joint erosions can occur. ${ }^{53}$ When synovial fluid has been examined it has been found to be inflammatory with a mononuclear cell infiltrate consisting mainly of lymphocytes, most of which carry the phenotype of activated suppressor/cytotoxic T cells. ${ }^{54}$

A low grade myositis is commonplace. Lakhampal et al reported abnormal electromyograms in 11 of 15 patients tested. ${ }^{51}$ Although only one had a raised serum creatine kinase level, four had low grade myositis on biopsy.

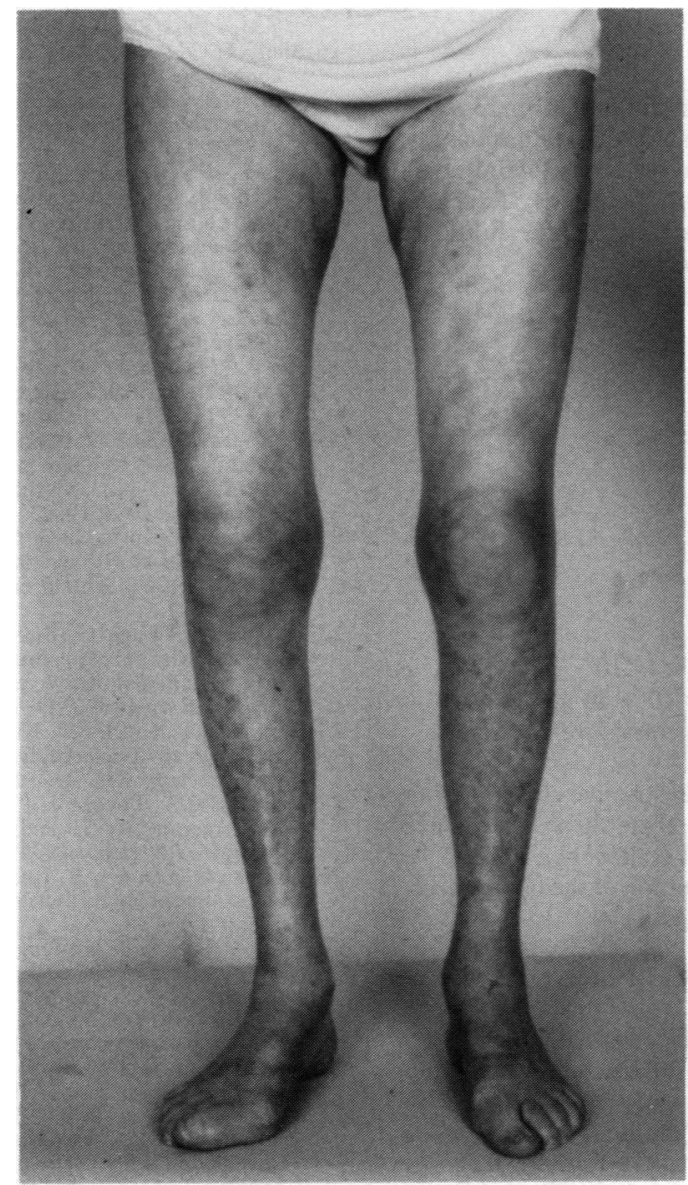

Figure 2 Clinical involvement of the legs in eosinophilic fasciitis showing tense induration of the skin.
Associated haematological disease is commonly reported. This includes aplastic anaemia, attributed in some cases to a serum inhibitor of erythroid stem cells, and thrombocytopenia associated in some cases with antibodies to platelets. ${ }^{55}$ Malignant transformation is also seen. ${ }^{56}$

Blood eosinophilia, often impressive, is the most striking laboratory abnormality. Eosinophilia greater than $7 \%$ of the differential count occurs in over $60 \%$ of cases. Peripheral eosinophilia can be transient, however, even in the absence of corticosteroid treatment, and the diagnosis of eosinophilic fasciitis should not be dismissed because of a normal laboratory finding. Similarly, tissue eosinophilia seen on histological examination of the fascia correlates with the presence or absence of a peripheral eosinophilia. Antinuclear antibodies, which characterise systemic sclerosis, are not found in eosinophilic fasciitis.

A deep biopsy, which must include tissue from the epidermis to skeletal muscle including the deep fascia, confirms the diagnosis (fig 3). Changes range from inflammation with minimal connective tissue change or connective tissue alteration to severe sclerosis. The deep fascia and septa of the subdermal fat are most extensively affected, whereas the epidermis is normal or only slightly atrophic. Some studies emphasise that there is overlap of histological features with systemic sclerosis. ${ }^{57}$ Tissue eosinophilia, for example, is also a feature of about $20 \%$ of patients with systemic sclerosis.

Initial reports suggest that eosinophilic fasciitis is a condition responsive to corticosteroids with a benign course. This, however, is not borne out in all cases described, and effects of therapeutic intervention must be judged against

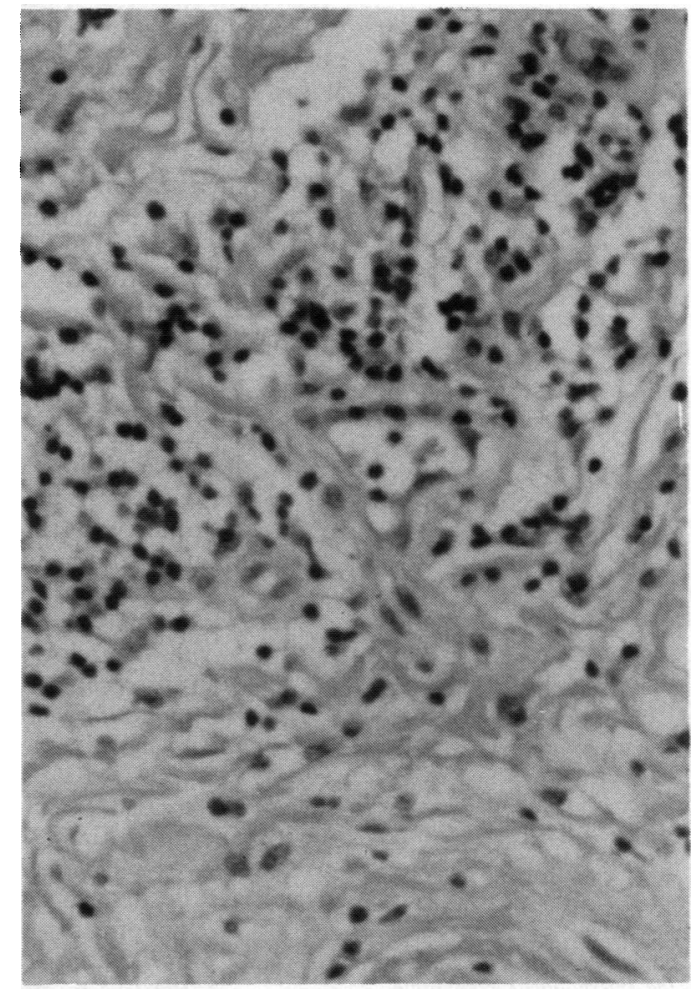

Figure 3 Histological features of eosinophilic fasciitis, including eosinophilic infiltration and fibrosis of the deep fascia. 
the background of spontaneous resolution, which occurs within three to five years of onset in a large proportion of cases. Relapses, although unusual, do occur. A clinical response to high dose prednisolone is expected in about $70 \%$ (remission in $15 \%$, partial improvement in the rest) irrespective of when in the course the drug is given. The erythrocyte sedimentation rate and eosinophilia nearly always respond, but in some cases the disease progresses despite normal laboratory values. Various other agents have been used, and reports suggest that a response to hydroxychloroquine is more consistently seen than to colchicine or penicillamine. One patient with carcinoma of the breast showed marked improvement after mastectomy. ${ }^{51}$

\section{Appendix: Proposed criteria for MCTD*}

Sharp et al ${ }^{19}$

Major criteria

1 Myositis, severe

2 Pulmonary disease

(a) CO diffusing capacity $<70 \%$ normal lung

or (b) Pulmonary hypertension

or (c) Proliferative vascular lesions on lung biopsy

3 Raynaud's phenomenon or oesophageal hypomotility

4 Swollen hands or sclerodactyly

5 Highest noted anti-extractable nuclear antigen titre $\geqslant 1 / 10000$ and anti-UIRNP positive and anti-Sm negative

Definite diagnosis $=4$ major criteria .

Alarcon-Segovia et al ${ }^{19}$

1 Serological

Positive anti-RNP at a haemagglutination titre of $1 / 1600$ or higher

2 Clinical (at least three†)

Oedema of hands

Synovitis

Myositis (proved by laboratory findings or biopsy)

Raynaud's phenomenon (two or three colour phase)

Acrosclerosis (with or without proximal scleroderma)

†The association of oedema of the hands, Raynaud's phenomenon, and acrosclerosis requires the addition of at least one of the other two criteria.

Kasukawa et al ${ }^{19}$

I Common symptoms

1 Raynaud's phenomenon

2 Swollen fingers or hands

II Anti-nRNP antibody

III Mixed findings

(A) SLE-like findings

1 Polyarthritis

2 Lymphadenopathy

3 Facial erythem

4 Pericarditis or pleuritis

5 Leucocytopenia $\left(<4 \times 10^{9} \quad\right.$ cells/l $)$ or thrombocytopenia $\left(<100 \times 10^{9}\right.$ platelets $\left./ 1\right)$

(B) Progressive systemic sclerosis-like findings

1 Sclerodactyly

2 Pulmonary fibrosis, restrictive change of lung (vital capacity less than $80 \%$ ) or reduced diffusion capacity ( $T_{L}$ co less than $70 \%$ )

3 Hypomotility or dilatation of the oesophagus

(C) Polymyalgia like findings

1 Muscle weakness

2 Increased serum level of myogenic enzymes (creatine kinase)

3 Myogenic pattern in electromyograph

Diagnosis 1 Positive in either of one of two common symptoms

2 Positive anti-RNP antibody

*Adapted from the Proceedings of the international symposium on mixed connective tissue disease and anti-nuclear
antibodies Tokyo, $29-30$ August 1986. ${ }^{18}$

3 Positive in one or more findings in two or three disease categories of $\mathrm{A}, \mathrm{B}$, and $\mathrm{C}$.

Diagnosis for MCTD is positive when diagnosis points 1 2 , and 3 are all fulfilled.
1 Subcommittee for scleroderma criteria of the American Rheumatism Association diagnostic and therapeutic criteria committee. Preliminary criteria for the classification of systemic sclerosis (scleroderma). Arthritis Rheum 1980; 23: 581-90.

2 Tan E M, Cohen A S, Fries J F, et al. The 1982 revised criteria for the classification of systemic lupus erythematosus. Arthritis Rheum 1982; 25: 1271-7.

3 Le Roy E C, Maricq H, Kahaleh M. Undifferentiated connective tissue syndrome. Arthritis Rheum 1980; 23: 341-3.

4 Dubois E L, Condon S, Friou G J, Buschel M. Progressive systemic sclerosis (PSS) and localized scleroderma (morphea) with positive LE cell test and unusual systemic (morphea) with positive LE cell test and unusual systemic manifestations compatible with systemic lupus eryt

5 Clark J A, Winkelmann R K, Ward E. Serologic alterations in scleroderma and sclerodermatomyositis. Mayo Clin Proc $1971 ; 46: 104-7$

6 Tuffanelli D L, Winkelmann R K. Systemic scleroderma. A clinical study of 727 cases. Arch Dermatol 1961; 84: 359-71.

7 Kantor G L, Bickel J B, Barnett E V. Coexistence of systemic lupus erythematosus and rheumatoid arthritis. Report of a case and review of the literature with clinical, pathologic and serologic observations. Am F Med 1969; 47: 443-54.

8 Droxos A A, Andonopoulos A P, Costopoulos J S, Stavropoulos E D, Papademetriou C S, Moutsopoulos H M. Siögren's syndrome in progressive systemic sclerosis. Sjogren's syndrome in progr

9 Reichlin M, Maddison P J, Targoff I, et al. Antibodies to a nuclear/nucleolar antigen in patients with polymyositis overlap syndromes. $\mathcal{F}$ Clin Immunol 1984; 4: 40-

10 Mimori T, Akizuki M, Yamagata $H$, Inada S, Yoshida S, Homma $M$. Characterization of a high molecular weight acidic nuclear protein recognized by autoantibodies in the sera from patients with polymyositis-scleroderma overlap. f Clin Invest 1981; 68: 611-7.

11 Wasicek C A, Reichlin M, Montes M, Raglan G. Polymyositis and interstitial lung disease in a patient with anti Jo-1 prototype. Am F Med 1984; 76: 538-44.

12 Harley J B, Sestak A L, Willis L G, Fu S M, Hanten J A, Reichlin M. A model for disease heterogeneity in systemic lupus erythematosus. Arthritis Rheum 1989; 32: 826-35.

13 Stephens A F, McHugh N J, Maddison P J, Isenberg D A, Welsh K I, Panayi G S. HLA class II restriction of autoantibody production in patients with systemic lupus eryantibody production in patients with

14 Yaneva M, Arnett F C. Antibodies against Ku protein in sera from patients with autoimmune disease. Clin Exp Immunol 1989; 76: 366-72.

15 Arnett F C, Goldstein R, Duvic M, Reveille J D. Major histocompatibility complex genes in systemic lupus erythematosus, Sjögren's syndrome and polymyositis. Am f Med 1988; 85 (suppl 6A): 38-41.

16 Sharp G C, Irving W, Tan E, Gould G, Holman H. Mixed connective tissue disease: an apparently distinct rheumatic disease syndrome associated with a specific antibody to an disease syndrome associated with a specific antibody to an 148-59.

17 Habets W J, de Rooij D J, Salden M H, Van Venrooij W R. Antibodies against distinct nuclear matrix problems are Antibodies against distinct nuclear matrix problems are characteristic for mixed connol

18 Sharp G C. Diagnostic criteria for classification of MCTD. In: Kasukawa R, Sharp G C, eds. Mixed connective tissue diseases and anti-nuclear antibodies. Amsterdam: Elsevier, 1987: 23-32.

19 Alarcon-Segovia D, Cardiel M M. Comparison between 3 diagnostic criteria for mixed connective tissue disease. Study of 593 patients. F Rheumatol 1989; 16: 328-34.

20 Ginsburg W, Conn D, Bunch M W, McDuffie F. Comparison of clinical and serologic markers in systemic lupus erythematosus and overlap syndrome: a review of 247 patients. matosus and overlap syndrom

21 Lazaro M A, Morteo O G. Clinical and serologic characteristics of patients with overlap syndrome: is mixed connective tics of patients with overlap syndrome: is mixed connective 68: $281-9$.

22 Petterson I, Wang G, Smith E, et al. Analysis of sera of patients with mixed connective tissue disease and systemic lupus erythematosus. A cross sectional longitudinal study. Arthritis Rheum 1986; 29: 986-96.

23 Winfield J B, Koffler D, Kunkel H G. Development of antibodies to ribonucleoproteins following short term therapy with procainamide. Arthritis Rheum 1975; 18: 531-6.

24 Kahn M-K A, Bovogeois P, Aeschlimann A, de Truchis P. Mixed connective tissue disease after exposure to poly vinyl chloride. F R heumatol 1989; 16: 533-5.

25 Veltman G, Lange C E, Juke S, et al. Clinical manifestations and course of vinyl chloride disease. Ann NY Acad Sci 1975; 246: 6-17.

26 Black C, Pereira S, McWhirter A, et al. Genetic susceptibility to scleroderma-like syndrome in symptomatic and asymptomatic workers exposed to vinyl chloride. $\mathcal{f}$ Rheumatol 1986; 13: 1059-62.

27 Kumagai Y, Shiokawa Y, Medsger T A, et al. Clinical spectrum of connective tissue disease after cosmetic surgery. rum of connective tissue dise

28 Black C M, Maddison P J, Welsh K I, Bernstein R, Woodrow J C, Pereira R S. HLA and immunoglobulin allotypes in J C, Pereira R S. HLA and immunoglobulin allotypes in mixed

29 Reilly P A, Evison G, McHugh N J, Maddison P J. Arthropathy of hands and feet in systemic lupus erythematosus. f Rheumatol 1990; 17: 777-84. 
30 Bennett R M, Bong D A, Spargo B $M$. Neuropsychiatric problems in MCTD. Am ₹ Med 1979; 65: 955-60.

31 Koboyashi S, Magase M, Kimura M, Ohyama K, Ikeza M, Honda $\mathrm{N}$. Renal involvement in mixed connective tissue disease. Am F Nephrol 1985; 5: 282-7.

32 Sullivan W D, Hurst D J, Harman C E, et al. A prospective evaluation emphasizing pulmonary involvement in patients evaluation emphasizing pulmonary involvement in patients with mixed con

33 Alpert M A, Goldberg S H, Singsen B H, et al. Cardiovascular manifestations of mixed connective tissue disease in adults. Circulation 1983; 68: 1182-8.

34 Nimelstein S H, Brody S, McShane D, Holman M R. Mixed connective tissue disease: a subsequent evaluation of the original 25 patients. Medicine (Baltimore) 1980; 59: 239-48.

35 Maricq H R, Le Roy E C, D'Angelo W A, et al. Diagnostic potential of in vivo capillary microscopy in scleroderma and related disorders. Arthritis Rheum 1980; 23: 183-9.

36 Potter J S, Gabor G T, Porter J M, Bennett R M. Angiographic findings in mixed connective tissue disease. Arthritis Rheum 1985; 28: 768-74.

37 Van Venrooii W J, Sillekens P T G. Small nuclear RNA associated proteins: autoantigens in connective tissue diseases. Clin Exp Rheumatol 1989; 7: 635-45.

38 Habets W J A Hoet M N, Sillekens P T G, De Rooij D, Van de Putte L B A, Van Venrooij W J. Detection of autoantibodies in a quantitative immunoassay using recombinan ribonucleoprotein antigens. Clin Exp Immunol 1989; 76: 172-7.

39 McHugh N, James I, Maddison P. Clinical significance of antibodies to a $68 \mathrm{kD}$ UIRNP polypeptide in connective tissue disease. 7 Rheumatol 1990; 17: 1320-8.

40 De Rooij D J R A M, Habets W J, Van de Putte L B A, Hoet $M H$, Verbeek $A$, van Venrooij $W J$. Use of recombinant RNP peptides $70 \mathrm{~K}$ and $A$ in an ELISA for measurement of antibodies in mixed connective tissue disease: a longi tudinal follow up of 18 patients. Ann Rherm Dis 1990; 49: 391-5.

41 Shulman L E. Diffuse fasciitis with hypergammaglobu linaemia and eosinophilia in a new syndrome. 7 R hermatol linaemia and eosinoph

42 Sibrack L A, Mazur E M, Hoffman R, Bollet A J. Eosinophilic fasciitis. Clin Rheum Dis 1982; 812: 443-54

43 Thomson G T D, Macdougall S, Watson P M, Chalmers I M. Eosinophilic fasciitis in a pair of siblings. Arthritis Rheum 1989; 32: 96-9.
44 Medsger T A, Nixon J A, Garwood V F. Palmar fasciitis and polyarthritis associated with ovarian carcinoma. Arch Intern Med 1982; 96: 424-31.

45 Seaman J M, Goble M, Madsen L, Steigerwald J C. Fasciitis and polyarthritis during antituberculous therapy. Arthritis Rheum 1985; 28: 1079-84.

46 Buchanan R, Gordon D, Muckle T, McKenn F, Kraag G. The eosinophilic fasciitis syndrome after phenytoin The eosinophilic fasciitis syndrome after

47 CDC. Update: eosinophilia-myalgia syndrome associated with the ingestion of $L$-tryptophan-United States as of January 9, 1990. MMWR 1990; 39: 14-15.

48 Flannery $M$, Wallach $P$, Espinoza $L$, Dohrenwent $M$ Moscinski L. A case of the eosinophilia-myalgia syndrom associated with the use of an L-tryptophan product. Ann Intern Med 1990; 112: 300-1.

49 Kaufman L D, Seidman R J, Gruber B L. L-tryptophan associated eosinophilic perimyositis, neuritis and fasciitis: a clinico pathological and laboratory study of 25 patients. Medicine (Baltimore) 1990; 69: 187-99.

50 Stachon A, Jablonska S, Kencka D. Tryptophan metabolism in scleroderma and eosinophilic fasciitis. In: Black C in scleroderma and eosinophilic fasciitis. In: Black C, Myers A, eds. Current topics in rheumatology: systemic sclerosis

51 Lakhampal S, Ginsburg $W W$, Michet J J, Doyle J A, Breanndan Morre S. Eosinophilic fasciitis: clinical spectrum and therapeutic response in 52 cases. Semin Arthritis Rheum 1988; 17: 221-31.

52 Amdur H S, Levin R E. Eosinophilic fasciitis during pregnancy. Obstet Gynecol 1989; 73: 843-7.

53 Pressly T A, Treadwell E L, Ansbacker L E, Winkler A, Hoyt T D, Walker S E. Eosinophilic fasciitis with porphyria cutanea tarda and progressive destructive arthritis. f Rheumatol 1989; 16: 390-3.

54 Campbell S M, Smith D L, Bakke A. Synovial fluid lymphocytes in eosinophilic fasciitis. $\mathcal{F}$ R heumatol $1989 ; 16: 239-41$.

55 Weltze M, Salvado A, Rosse W, et al. Humoral suppression of haematopoiesis in eosinophilic fasciitis. Blood 1978; 52 (suppl): 218 .

56 Michaels R M. Eosinophilic fasciitis complicated by Hodgkin's disease. $\mathcal{F}$ R heumatol 1982; 9: 473-6.

57 Magaro M, Altomoute L, Zoli A, Mirone L, Massi G, Federico $F$. Eosinophilic fasciitis associated with inflammatory neutrophilic vasculitis. BrF Rheumatol 1990; 29: 145-6 